\title{
Compact Millimeter-Wave Switched-Beam Antenna Arrays for Short Range Communications
}

\author{
A. T. Alreshaid ${ }^{1}$, M. S. Sharawi ${ }^{1}$, S. Podilchak ${ }^{2}$ and K. Sarabandi ${ }^{3}$ \\ ${ }^{1}$ Electrical Engineering Department, King Fahd University of Petroleum \& Minerals, \\ Dhahran, 31261, Saudia Arabia. \\ Email: alreshaid@kfupm.edu.sa ; msharawi@kfupm.edu.sa \\ ${ }^{2}$ Institute of Sensors, Signals and Systems within the School of Engineering and Physical Sciences at \\ Heriot-Watt University, Edinburgh, Scotland, UK, EH14 4AS \\ Email: s.podilchak@hw.ac.uk \\ ${ }^{3}$ Electrical and Computer Engineering Department, \\ University of Michigan, Ann arbor, MI 48109 USA \\ Email: $\underline{\text { saraband@umich.edu }}$
}

\begin{abstract}
The need for more data throughput is a requirement that will keep growing in future wireless standards, and during the past few years, millimeter-wave technology has generated much excitement in the mobile and wireless communications sectors due to the large bandwidth it can offer. In this letter two different travelling-wave, slot antenna arrays are proposed which can offer tunable switched-beam capability at millimeter-wave frequencies. The antenna systems are built on a single layer PCB with top- and bottom-side etching for operation at $28 \mathrm{GHz}$ with at least $0.7 \mathrm{GHz}$ of measured impedance bandwidth. For the first design, a planar $2 \times 4$ slot antenna array is proposed while the second design is implemented using a $4 \times 4$ slot array to demonstrate improved beam directivity. A Butler matrix for simple beam switching in the far-field is also integrated within the compact antenna structure to provide the needed phased array operation. The total size of the two proposed systems with their feed networks are $55.2 \times 55 \times 0.13 \mathrm{~mm}^{3}$ and $53.7 \times 61.2 \times 0.13 \mathrm{~mm}^{3}$, respectively. These new travelling-wave switched beam arrays can be placed within current handheld mobile devices for high bandwidth short range communications enabling $5 \mathrm{G}$ technologies.
\end{abstract}

Key Words - Butler beam-forming network, millimeter-wave, slot antenna, switched beam, traveling-wave antenna, $\mathbf{5 G}$.

\section{INTRODUCTION}

The exponential increase in the volume of data traffic has motivated researchers to start exploring and nominating the millimeter-wave (mm-wave) spectrum as a candidate to provide channels with large bandwidths (BWs) for fifth generation $(5 \mathrm{G})$ wireless communication systems. All wireless standards operating in the frequency range from 700

This is the author manuscript accepted for publication and has undergone full peer review but has not been through the copyediting, typesetting, pagination and proofreading process, which may lead to differences between this version and the Version record. Please cite this article as doi:10.1002/ mop.29940. 
$\mathrm{MHz}$ to $2.6 \mathrm{GHz}$ have limited channel BWs, thus limiting the amount of data for transmission. By up converting the communication frequency to $28 \mathrm{GHz}$ or $38 \mathrm{GHz}$ the allocated $\mathrm{BW}$ can increase significantly, providing data speeds much higher than what is provided by the latest technology launched to-date, more specifically, long-term-evolution advanced (LTE-A).

This immediate need for high data throughput at millimeter-wave frequencies can be met by utilizing robust radio access technologies. However, when considering frequency systems operating around $60 \mathrm{GHz}$, for example, high path loss due to atmospheric absorption can be observed. On the other hand, it was recently found that the attenuation caused by this phenomena at $28 \mathrm{GHz}$ is only $0.012 \mathrm{~dB}$ over $200 \mathrm{~m}$ and $0.016 \mathrm{~dB}$ over the same distance at $38 \mathrm{GHz}$, thus providing a good frequency candidate for future wireless systems and enabling the possibility for high data rate throughputs with large BWs [1], [2]. Moreover, by taking advantage of the $28 \mathrm{GHz}$ operational frequency, the corresponding wavelength is much smaller than more conventional communication schemes and thus mobile devices can support more antenna elements and arrays for higher gain. This can compensate for the free-space path losses introduced in the millimeter-wave communications channel.

The design of such 5G mobile terminals employing compact and tunable traveling-wave arrays with switchedbeam capability, and other leaky-wave phased arrays [3] for wireless technologies at millimeter-wave frequencies, has not been widely investigated in the literature. There have been a few notable works at microwave frequencies where tunable series-fed patch antenna array elements, using new phased array approaches, have been demonstrated [4-6]. However, additional antenna research should be encouraged to meet the needs for beam controllable millimeter-wave antenna arrays enabling the aforementioned short-range communications. This is because with a limited number of radiating elements, compact series-fed antenna arrays can offer beam directivities on the order of $10 \mathrm{~dB}$ with half-power beam widths which are typically less than $8^{\circ}$.

To enable pattern control for these types of traveling-wave antennas using simpler phased array approaches, beamforming networks are needed for pattern switching and control in the far-field. The Butler network may be preferred for mobile communications since it is a relatively simple feeding structure with low-losses offering low-cost implementation and simple integration with hand-held terminals. Moreover, few works have concentrated on designing Butler networks at millimeter-wave frequency, such as [7] and [8] at $60 \mathrm{GHz}$, while the rest of the papers operated below $13 \mathrm{GHz}$ such as [9] and [10]. In [11], for example, a $24 \mathrm{GHz}$ Butler network was designed on silicon using $0.18 \mu \mathrm{m}$ CMOS technology with no antenna elements for radiation. It provided a BW of $2 \mathrm{GHz}$ where the core Butler circuitry was only $0.9 \mathrm{~mm}$ by $0.46 \mathrm{~mm}$, excluding the outer connections and the input/output ports. An integrated Butler with patches was designed in [11]. The operating frequency was $60 \mathrm{GHz}$ providing a BW of $3 \mathrm{GHz}$. The system was built on an RT/duroid 5880 substrate with dielectric constant of 2.2 and thickness of $0.127 \mathrm{~mm}$. The gain of the antennas was between 7 and $8.9 \mathrm{dBi}$. Most of the antennas for these systems were based on patches or quasi-yagi antennas in a linear array setup. 
In this work, we propose two versions of one of the first traveling-wave antenna arrays using a Butler matrix for switched-beam diversity at $28 \mathrm{GHz}$. The proposed designs (see Fig. 1) are implemented using an array of series-fed slots printed on a single layer PCB with top- and bottom-side etching. To our knowledge this is the first time that such traveling-wave phased arrays with an integrated beam forming network have been designed, measured, and experimentally verified, while also, offering simple low cost implementation. The first version of the system contains a $2 \times 4$ slot antenna array integrated with its Butler feed network, while the second version is a similar $4 x 4$ array. The measured $-10 \mathrm{~dB}$ impedance BWs were at least $0.8 \mathrm{GHz}$ and $0.7 \mathrm{GHz}$ for the $2 \mathrm{x} 4$ and the $4 \mathrm{x} 4$ array, respectively. In addition, measured gain values for the two designs ranged from 5 to $7 \mathrm{~dB}$ and simulations and measurements are presented demonstrating good performance for the compact switched-beam travelling-wave antennas.

\section{Design Details}

There are several configurations of networks that can provide multi/switched beam control, such as the Butler matrix, the phased array network, and the Rotman and Bootlace lenses [12]. They can be classified into different categories; active and passive, steering and non-steering, simple and complex. Each configuration has its own advantages and disadvantages. Due to the Butler network's advantages over other types like its compact design, passive architecture, and the absence of external control, it has been selected to feed the proposed traveling-wave antenna arrays, mainly, to offer low cost, switched beam capability and simple integration with other electronic components.

In this letter, the Butler beam forming network is $4 \times 4$, so the insertion phases feeding the traveling-wave arrays are $-135^{\circ},-45^{\circ},+45^{\circ}$ and $+135^{\circ}$ respectively. This can offer beam steering at broadside for the angles $-45^{\circ},-20^{\circ},+20^{\circ}$ and $+45^{\circ}$ in a transverse plane perpendicular to the system board. More specifically, our $4 \mathrm{x} 4$ Butler network for millimeter-wave frequencies consists of 4 couplers, 2 crossovers, and 4 phase delay lines. These feed systems and antenna arrays are built on a thin $(0.13 \mathrm{~mm})$ Rogers 3003 substrate with a dielectric constant of 3 to reduce surface wave excitation and improve radiation efficiency. According to these parameters, the width of the microstrip line is $0.33 \mathrm{~mm}$ to provide an impedance of $50-\Omega$. Also, the dimensions of the hybrid coupler arms are $0.19 \mathrm{~mm}$ by 2.44 $\mathrm{mm}$ for the thin arm $(50-\Omega)$ and $0.41 \mathrm{~mm}$ by $2.2 \mathrm{~mm}$ for the thicker one $(35.35-\Omega)$. The crossover is achieved by cascading two of these hybrid couplers, which results in passing the two signals across each transmission line with the some loss and phase shift. Fig. 1 illustrates the layout of the two proposed antenna arrays while dimensions for their slot elements are described in Table I.

Table 1 Antenna Array Design Parameters for the two versions

Fig. 1 Layouts of Butler network integrated with a (a) 2x4 and a (b) $4 \times 4$ slot antenna array 
For an ideal Butler network, the injected signal is divided equally between the output ports with an expected insertion loss of $6 \mathrm{~dB}$ at the output terminals. The challenge in the design is to minimize the losses and maintain the required phase difference between the output ports feeding the traveling-wave antenna arrays over a large operating bandwidth. In beam switching operation, one port is excited at a time, giving rise to one out of four beam directions. Other wideband designs have also been implemented and reported in the literature as recently reported in [13].

The slot antenna element is chosen in this work because of its easy implementation and simple integration within the ground plane. The designed slot antenna, which has a width of $0.4 \mathrm{~mm}$, is fed by the $50-\Omega$ microstrip feeding line. For the $2 \times 4$ structure, the slot's center is shifted by $1.3 \mathrm{~mm}$ from the center of the feeding line for $50-\Omega$ matching. It has a length of half a wavelength, which has been optimized through simulations to $3.45 \mathrm{~mm}$. The spacing between the centers of the adjacent slots is $6.9 \mathrm{~mm}$. The proposed planar arrays utilize parallel feeding such that each microstrip feeding line excites a series array of slots defining a traveling-wave antenna. As a result, the overall size of the $2 \times 4$ and $4 \times 4$ antenna systems are $55.2 \times 55 \times 0.13 \mathrm{~mm}^{3}$ and $53.7 \times 61.2 \times 0.13 \mathrm{~mm}^{3}$, respectively.

\section{RESULTS \& DISCUSSIONS}

The optimization and simulations of the design were performed using HFSS ${ }^{\mathrm{TM}}$. Also, the phase delay lines within the feeding network were optimized to provide the required insertion phases at the input of the antenna arrays. Due to the use of mini-SMP connectors as external ports in the individual Butler design, as well as inputs in the complete system design, pads were placed around the ports with ground connected vias. The use of mini-SMP connectors also placed another restriction which was that the minimum distance between the input lines had to be greater than $5 \mathrm{~mm}$ [14]. This resulted in an increased separation of the input mini-SMP connectors from the Butler matrix feed system

When port 1 was excited, within the Butler matrix, the simulated power levels detected at the output ports varied from -10.4 to $-6.1 \mathrm{~dB}$ while they varied from -9.3 to $-7.6 \mathrm{~dB}$ for port 2 . For the phases when port 1 was excited, the phase differences between the output ports was $-51.5^{\circ}$ between ports 5 and $6,-42.5^{\circ}$ between ports 6 and 7 , and $-48.9^{\circ}$ between ports 7 and 8 . That introduces an average error of $4^{\circ}$ from the ideal difference of $-45^{\circ}$. For the second port, the differences were $144.4^{\circ}, 133.4^{\circ}$ and $122.74^{\circ}$ which make an average phase shift of $7.7^{\circ}$ from the ideal values of $135^{\circ}$. Tuning the network to obtain the required phase differences between the output ports was quite challenging. That was due to two main factors. The first one was to monitor the amplitude response and not to introduce more losses, while the second issue was the difficulty of tuning the phase differences between all the array input phases.

Fig. 2 shows the simulated reflection coefficient curves for all input ports for the $4 \times 4$ design as well as its port coupling. A slight shift in the desired resonance frequency is observed (i.e. now it is $29 \mathrm{GHz}$ ). Similar values were observed for the $2 \times 4$ antenna structure. The simulated 3D gain patterns for the complete millimeter-wave, switched beam traveling-wave antenna array are shown in Fig. 3. A maximum value of approximately $4.6 \mathrm{~dB}$ was pointing at $\theta$ $=45^{\circ}$ and $135^{\circ}$ from the $\mathrm{z}$-axis when port 1 was excited for the $4 \times 4$ array. When port 2 was excited, the beam went to 
$-20^{\circ}$ and $-160^{\circ}$, with $6.5 \mathrm{dBi}$ gain. Similar behavior was observed for the $2 \mathrm{x} 4 \mathrm{design}$, with slightly lower gain values (4.1 and $6.4 \mathrm{dBi}$ for ports 1 and 2 , respectively). The other two ports behaved similarly.

Fig. 2 Simulated port parameter curves for the $4 \times 4$ antenna array, (a) reflection coefficients, (b) port coupling.

Fig. 2 Simulated 3D Gain pattern for the $4 \mathrm{x} 4$ antenna array integrated with Butler at $28.5 \mathrm{GHz}$ when (a) port 1 or (b) port 2 is excited

Photographs of the fabricated prototypes are shown in Fig. 4 with front and back views. The responses experienced a frequency shift of approximately $1 \mathrm{GHz}$ when comparing simulations against measurements due to the fabrication tolerances and possible material variations. In addition, the connector model was not incorporated into the simulations, only its pad. The measured input port S-parameters for the two designs are shown in Fig. 5 and were conducted at KFUPM, Saudi Arabia, using an Agilent PNA (N5572A). As can be noted from Fig. 5(a), port 1 of the 2x4 antenna array system has a BW of $720 \mathrm{MHz}$ centered at $26.64 \mathrm{GHz}$ and $800 \mathrm{MHz}$ from 27.44 to $28.44 \mathrm{GHz}$. A one $\mathrm{GHz} \mathrm{BW}$ is achieved by port 2 centered at $25.95 \mathrm{GHz}$. It also has a BW of $760 \mathrm{MHz}$ centered at $27.7 \mathrm{GHz}$. It can be summarized that the $2 \times 4$ antenna array provided a BW of about $0.8 \mathrm{GHz}$ centered around $27.8 \mathrm{GHz}$ for all ports. For the $4 \times 4$ design, port 1 achieved a measured BW of $1.24 \mathrm{GHz}$ centered at $28.3 \mathrm{GHz}$. The second port has 720 $\mathrm{MHz}$ centered at $27.9 \mathrm{GHz}$ and $1.04 \mathrm{GHz}$ at $26.1 \mathrm{GHz}$. The overall $\mathrm{BW}$ of the $4 \mathrm{x} 4$ array is about $0.8 \mathrm{GHz}$ centered at $28 \mathrm{GHz}$.

Fig. 4 The top view of the fabricated models for the: (a) $2 \times 4$ and (b) $4 \times 4$ antenna array. Inset pictures show the back view of the antennas.

Fig. 3 Measured reflection coefficients for (a) the $2 \times 4$ antenna array system (b) the $4 \times 4$ antenna array system

The radiation patterns for both designs were measured in the anechoic chamber facility at the Royal Military College of Canada, ON, Canada, and the University of Michigan, Ann Arbor, USA. Figs. 6(a) and (b) show the normalized measured patterns for the two arrays for their upper halves. The beams were successfully steered from broadside with peak gains ranging from 5 to $7 \mathrm{dBi}$. The $2 \times 4$ array had wider beamwidths for ports 2,3 compared to 1,4 , while the $4 \times 4$ array had comparable beamwidths for all ports due to array symmetry.

Fig. 6 Measured patterns at (a) $27.6 \mathrm{GHz}$ for the $2 \times 4$ antenna system for all ports, (b) $27.8 \mathrm{GHz}$ for the $4 \times 4$ antenna system for all ports (continous line co-pol values, dashed-dotted line x-pol levels). 


\section{CONCLUSIONS}

In this work, two versions $(2 \times 4$ and $4 \times 4)$ of millimeter-wave beam switching antenna arrays have been designed, fabricated and measured. The feeding network was based on a Butler matrix and slot elements were employed within the traveling-wave phased arrays. The overall antenna sizes were $55.2 \mathrm{~mm}$ by $55.0 \mathrm{~mm}$ by $0.13 \mathrm{~mm}$ and $53.7 \mathrm{~mm}$ by $61.2 \mathrm{~mm}$ by $0.13 \mathrm{~mm}$, nominating them as suitable short-range solutions for handheld devices. The minimum measured BWs were $0.8 \mathrm{GHz}$ and $0.7 \mathrm{GHz}$ for the $2 \times 4$ and the $4 \times 4$ antenna structures, respectively, and both cover the $28 \mathrm{GHz}$ band of operation. The peak gain for the antenna systems (feed network and arrays) ranged from 5 to 7 $\mathrm{dB}$.

\section{ACKNOWLEDGEMENTS}

The authors would like to acknowledge the support provided by the Deanship of Graduate Research (DSR) at King Fahd University of Petroleum and Minerals (KFUPM), Dhahran, Saudi Arabia, under project number RG1332.

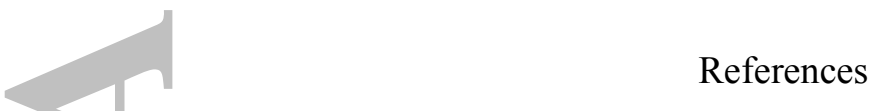

1. T. S. Rappaport, S. Sun, R. Mayzus, H. Zhao, Y. Azar, K. Wang, G. N. Wong, J. K. Schulz, M. Samimi and F. Gutierrez, Millimeter Wave Mobile Communications for 5G Cellular: It Will Work!, IEEE Access, 2013, 335 - 349.

2. T. Rappaport, F. Gutierrez, E. Ben-Dor, J. Murdock, Y. Qiao and J. Tamir, Broadband Millimeter-Wave Propagation Measurements and Models Using Adaptive-Beam Antennas for Outdoor Urban Cellular Communications, IEEE Trans. on Ant, and Prop., 61(2013), 1850-1859.

3. P. Baccarelli, P. Burghignoli, C. Di Nallo, F. Frezza, A. Galli , P. Lampariello and G. Ruggieri Full-wave analysis of printed leaky-wavephased arrays, Int. J. RF Microwave Comput. Aided Eng., 12(2002), 272 -287.

4. M.A.Y.Abdalla and G.V. Eleftheriades, A Planar Electronically Steerable Patch Array Using Tunable PRI/NRI Phase Shifters, IEEE Trans. on Microwave Theory and Techniques, 57(2009), 531-541.

5. Y.K. and B. Lee, Beam scannable patch array antenna employing tunable metamaterial phase shifter, IEEE Antennas and Propagation Society International Symposium (APSURSI), 2012.

6. P. Loghmannia, M. Kamyab, M. RanjbarNikkhah and R. Rezaiesarlak, Miniaturized Low-Cost Phased Array Antenna Using SIW Slot Elements, IEEE Ant. Wir. Prop. Lett, 11(2012), 1434-1437.

7. C.-H. Tesng, C.-J. Chen, and T.-H. Chu, A Low-Cost 60-GHz Switched-Beam Patch Antenna Array With Butler Matrix Network, IEEE Ant. Wir. Prop. Lett., 7(2008), 432-435.

8. C. E. Patterson, W. T. Khan, G. E. Ponchak, G. S. May and J. Papapolymerou, A 60-GHz Active Receiving SwitchedBeam Antenna Array With Integrated Butler Matrix and GaAs Amplifiers, IEEE Trans. on Microwave Theory and Techniques, 60(2012), 3599-3607.

9. S. Gruszczynski and K. Wincza, Broadband $4 \times 4$ Butler Matrices as a Connection of Symmetrical Multisection CoupledLine 3-dB Directional Couplers and Phase Correction Networks, IEEE Trans. on Microwave Theory and Techniques, 57(2009), 1-9.

10. C. Liu, S. Xiao, Y.-X. Guo, M.-C. Tang, Y.-Y. Bai and B.-Z. Wang, Circularly Polarized Beam-Steering Antenna Array With Butler Matrix Network, IEEE Ant. Wir. Prop. Lett., 10(2011), 1278 -1281.

11. T.-Y. Chin, S.-F. Chang, C.-C. Chang and J.-C. Wu, A 24-GHz CMOS Butler Matrix MMIC for multi-beam smart antenna systems, Radio Frequency Integrated Circuits Symposium,2008, pp. 633-636.

12. R. L. Haupt, Array Beamforming Networks, in Antenna Arrays - A Computational Approach, Hoboken, New Jersey, John Wiley \& Sons, Inc. 2010, pp. 408-460.

13. O. Haraz and A.-R. Sebak, Two-layer butterfly-shaped microstrip $4 \times 4$ Butler matrix for ultra-wideband beam-forming applications, 2013 IEEE Inte. Conference on Ultra-Wideband (ICUWB), 2013.

14. Pasternack Enterprises, 2014: Mini SMP Male Full DetentConnector Solder Attachment Surface Mount PCB. Accessed 16 December 2015 [Available online at: http://www.pasternack.com/images/ProductPDF/PE44489.pdf.] 


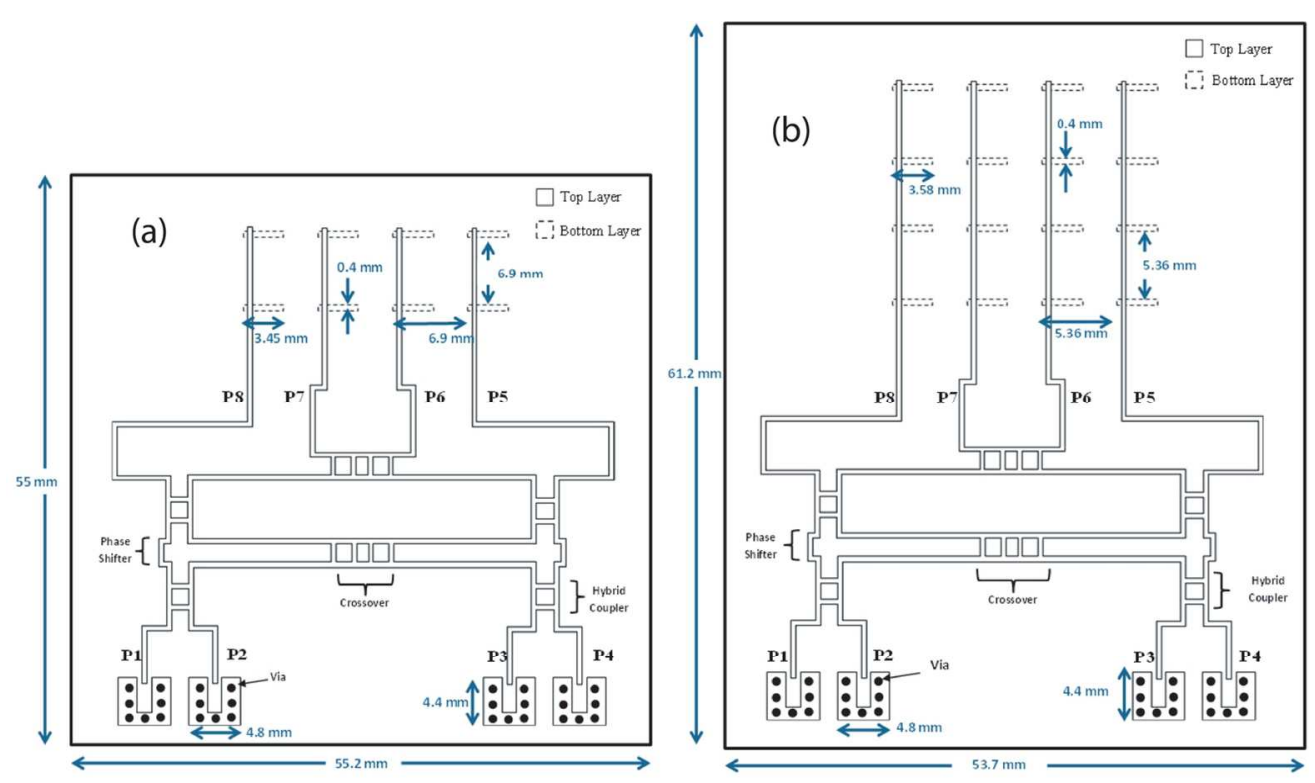

Fig1 Layouts of Butler network integrated with a (a) 2x4 and a (b) $4 \times 4$ slot antenna array $134 \times 78 \mathrm{~mm}(300 \times 300$ DPI) 

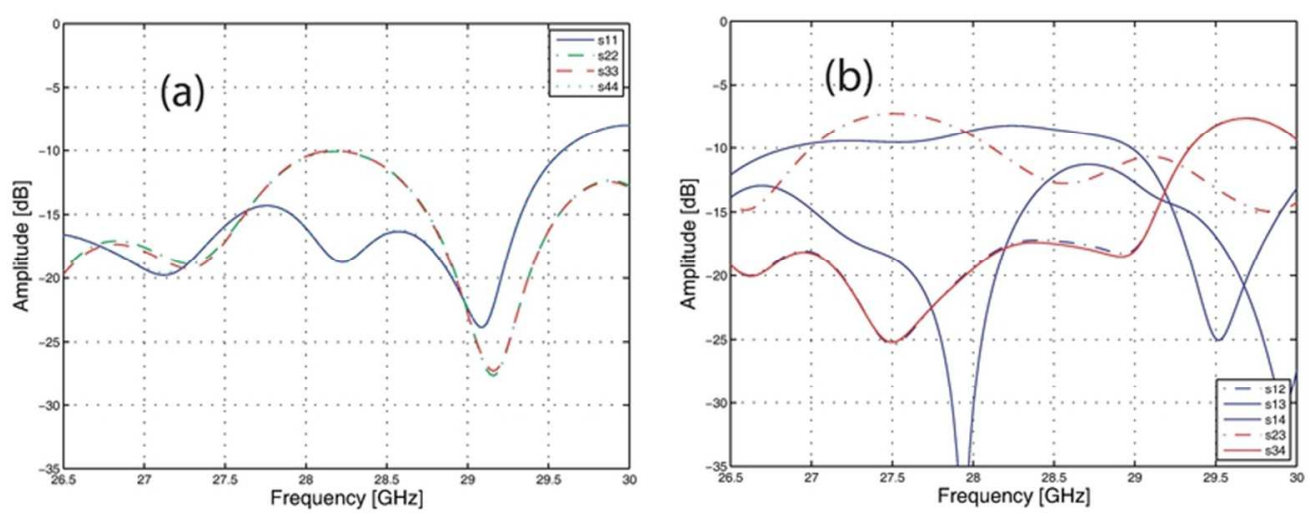

Fig 2 Simulated port paraemter curves for the $4 \times 4$ antenna array, (a) reflection coefficients, (b) port coupling.

$70 \times 27 \mathrm{~mm}(300 \times 300 \mathrm{DPI})$
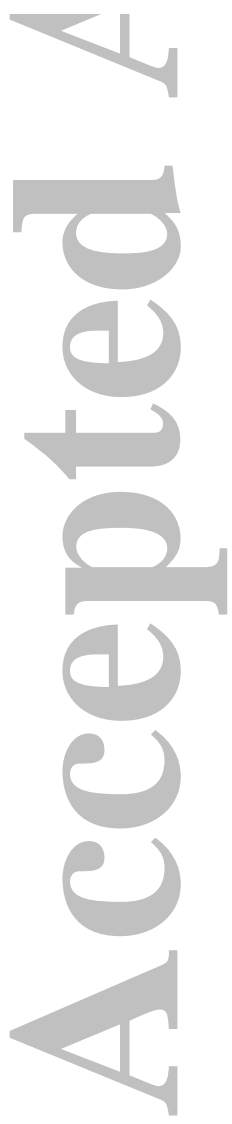

John Wiley \& Sons

This article is protected by copyright. All rights reserved. 


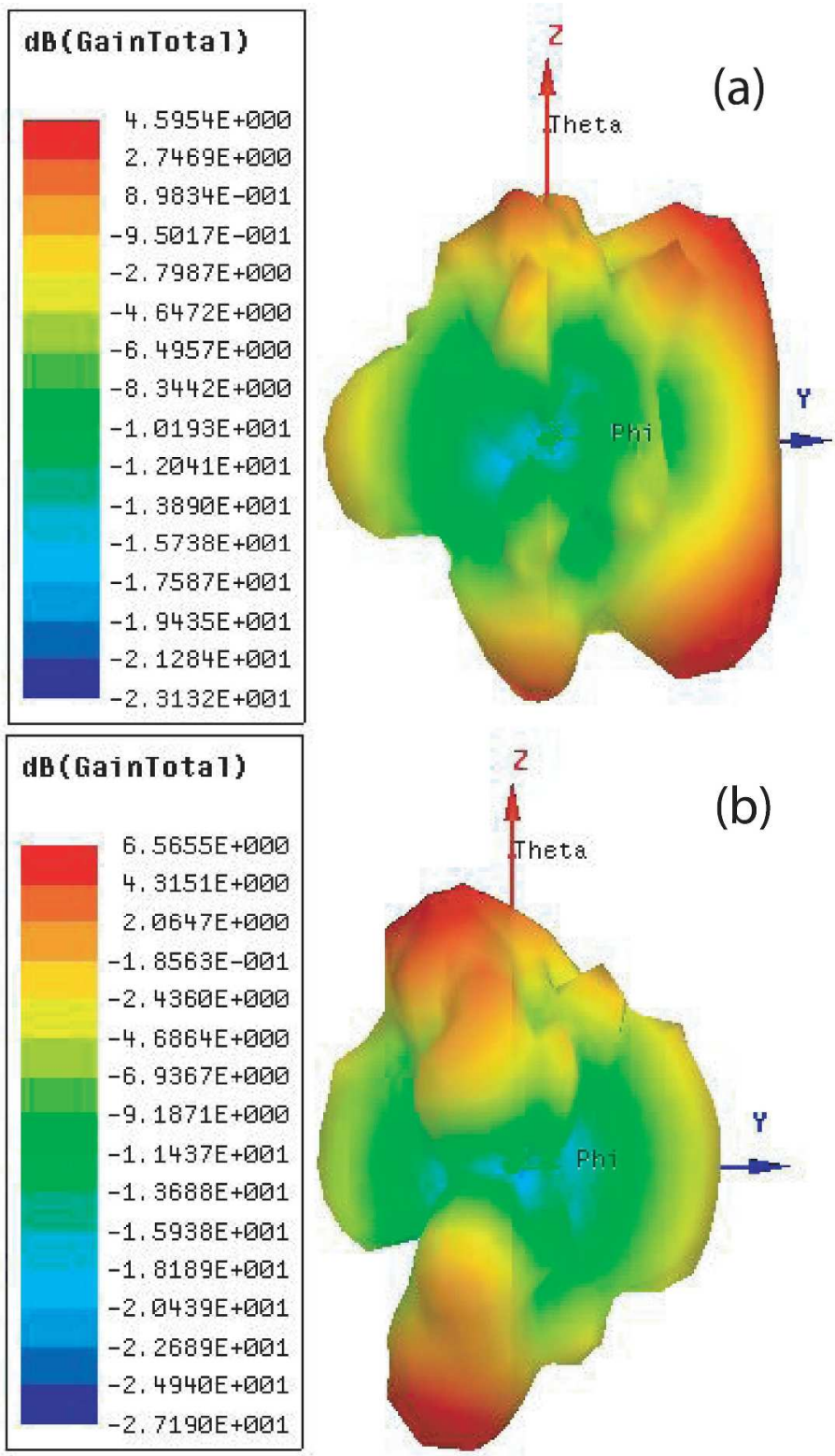

Fig3 Simulated 3D Gain pattern for the $4 \times 4$ antenna array integrated with Butler at $28.5 \mathrm{GHz}$ when (a) port 1 or (b) port 2 is excited $234 \times 399 \mathrm{~mm}(300 \times 300 \mathrm{DPI})$ 

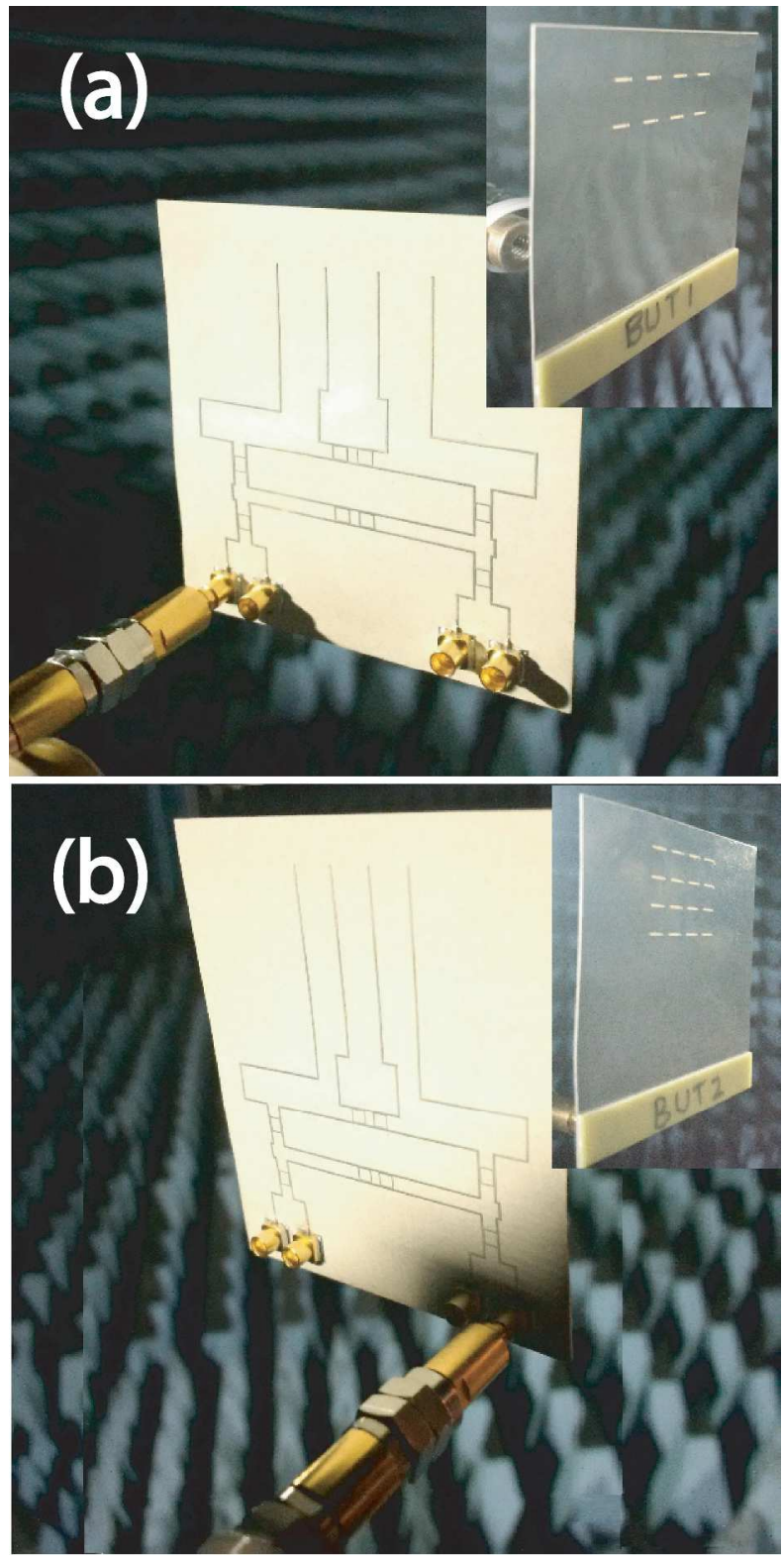

Fig 4 The top view of the fabricated models for the: (a) $2 \times 4$ and (b) $4 \times 4$ antenna array. Inset pictures show the back view of the antennas.

$216 \times 434 \mathrm{~mm}(300 \times 300 \mathrm{DPI})$

\section{John Wiley \& Sons}

This article is protected by copyright. All rights reserved. 

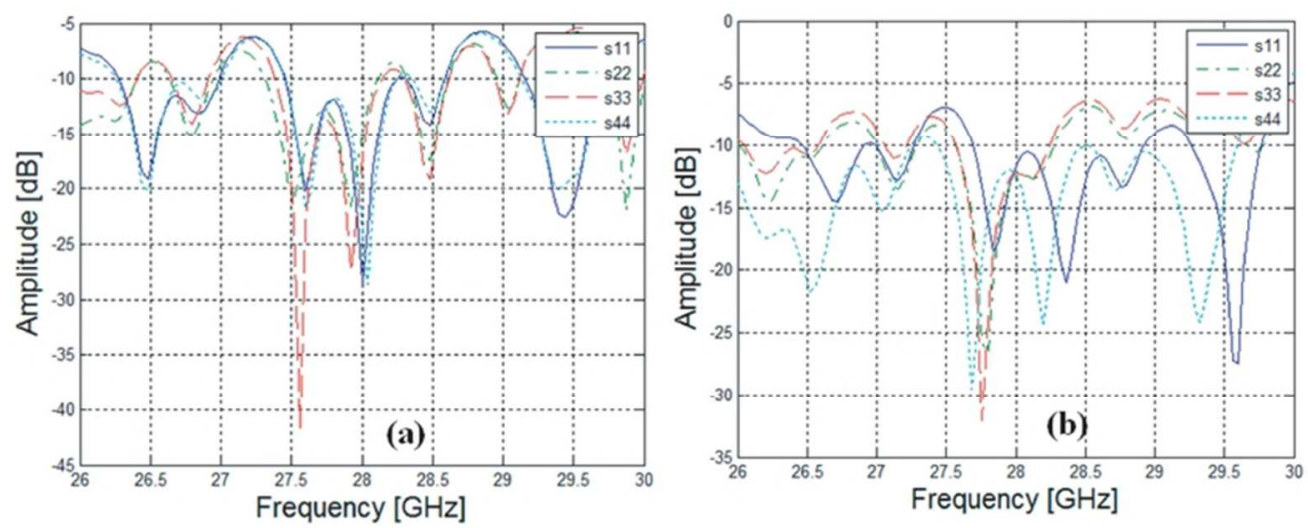

Fgi 5 Measured reflection coefficients for (a) the $2 \times 4$ antenna array system (b) the $4 \times 4$ antenna array system

$71 \times 28 \mathrm{~mm}(300 \times 300$ DPI $)$
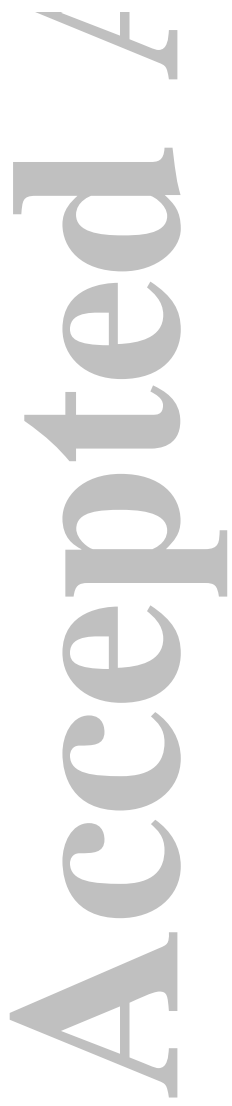

John Wiley \& Sons

This article is protected by copyright. All rights reserved. 


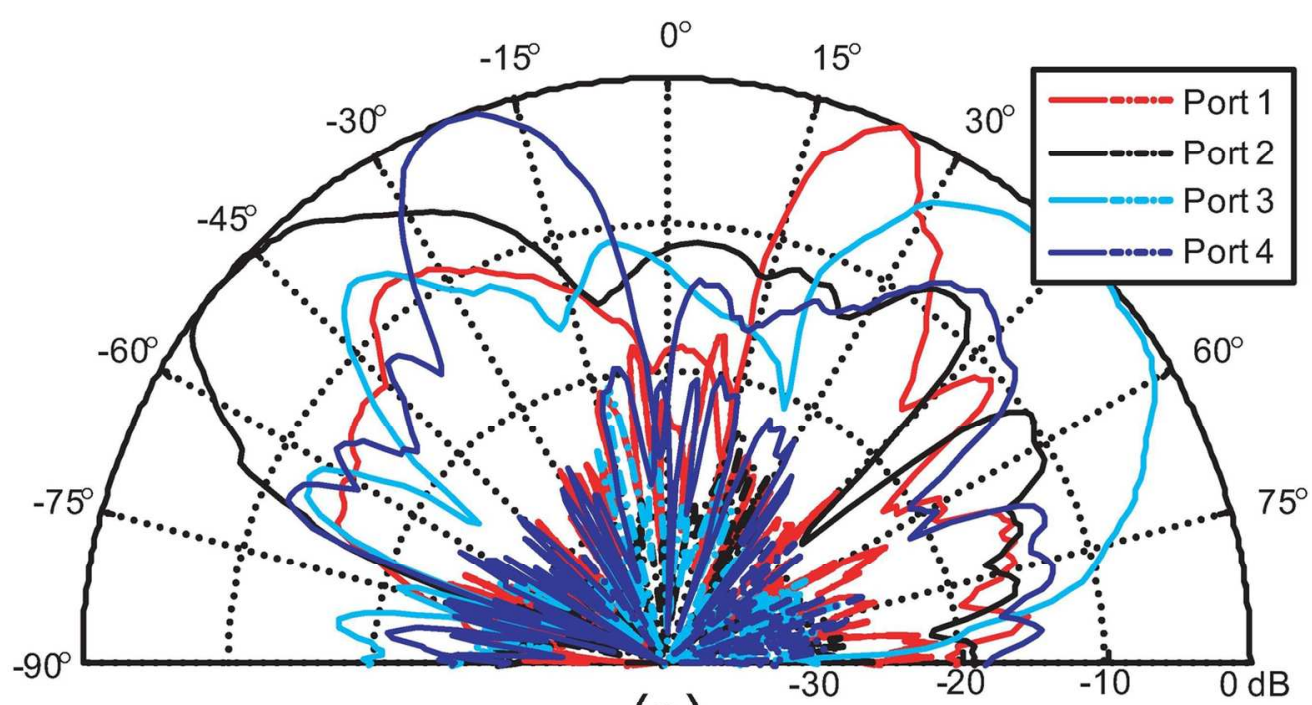

(a)

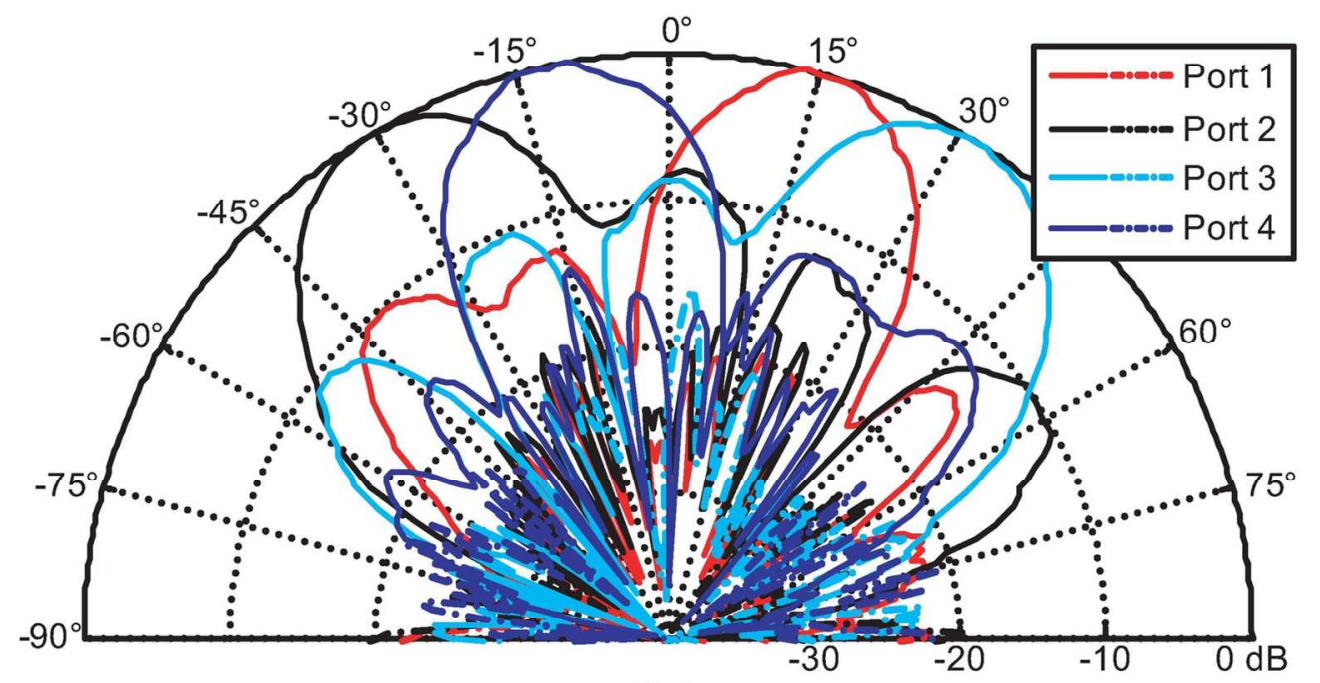

(b)

Fig 6 Measured patterns at (a) $27.6 \mathrm{GHz}$ for the $2 \times 4$ antenna system for all ports, (b) $27.8 \mathrm{GHz}$ for the $4 \times 4$ antenna system for all ports (continuous line co-pol values, dashed-dotted line $x$-pol levels). $132 \times 154 \mathrm{~mm}(300 \times 300 \mathrm{DPI})$ 

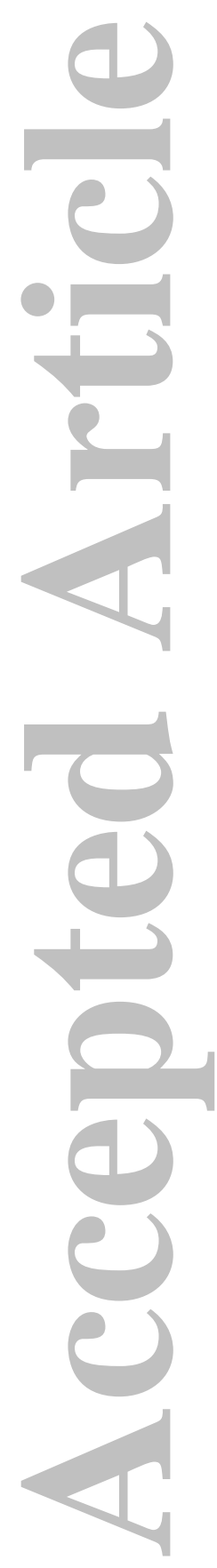

\begin{tabular}{|c|c|c|c|c|c|}
\hline & Slot's Width (mm) & Slot's Length (mm) & $\begin{array}{l}\text { Horizontal Shift from } \\
\text { feed's center (mm) }\end{array}$ & $\begin{array}{l}\text { Inter-element } \\
\text { Spacing (mm) }\end{array}$ & $\begin{array}{c}\text { \# elements per feed } \\
\text { (Series) }\end{array}$ \\
\hline Version I & 1 & & & $6 \mathrm{O}$ & 2 \\
\hline Version II & & This ardidelis pro & an Wiley \& Sons & x & 4 \\
\hline
\end{tabular}

